\title{
From Crisis To Crisis: Impacts Of The COVID-19 Pandemic On People Living With HIV And AIDS Service Organizations In Indiana
}

\author{
Justin J MacNeill \\ Purdue University \\ Jacqueline $C$ Linnes
}

Purdue University

Natalia M Rodriguez ( $\square$ natalia@purdue.edu )

Purdue University https://orcid.org/0000-0002-2633-4397

\section{Research Article}

Keywords: HIV, COVID-19, Socio-ecological model, AIDS Service Organizations

Posted Date: February 21st, 2022

DOI: https://doi.org/10.21203/rs.3.rs-1003567/v1

License: (c) (i) This work is licensed under a Creative Commons Attribution 4.0 International License.

Read Full License 


\section{Abstract}

Background: The COVID-19 pandemic thrust people living with HIV (PLWH) and HIV/AIDS service organizations into an environment ripe with uncertainty. This study examined Indiana AIDS services provider perceptions of how COVID-19 affected the overall health and access to care of their clients, and how the organizations prepared for, adapted, and responded to the needs of PLWH during the pandemic.

Methods: Guided by the socioecological model, fifteen semi-structured interviews were conducted with ten different HIV/AIDS service organizations across the state of Indiana.

Results: Despite the profound disruptions experienced by HIV programs, HIV/AIDS service organizations responded quickly to the challenges posed by the COVID-19 pandemic through myriad innovative strategies, largely informed by prior experiences with the HIV epidemic.

Conclusions: The lessons provided by HIV/AIDS service organizations are invaluable to informing future pandemic response for PLWH. Service delivery innovations in response to the COVID-19 crisis may provide insights to improve HIV care continuity strategies for vulnerable populations far beyond the pandemic.

\section{Background:}

Prior to the COVID-19 pandemic, human immunodeficiency virus (HIV) was a persistent public health crisis in the United States, especially among medically-underserved populations including racial and ethnic minorities (1), as well as people who use drugs (PWUD) who are 22 times more likely to acquire HIV than the average population (2). As of 2018, 1.2 million existing cases of HIV, along with 38,000 new annual diagnoses were documented in the United States, with approximately 86 percent of the existing population aware of their status (1).

The onset of COVID-19 precipitated a national environment especially precarious for people living with HIV (PLWH). Not only has COVID-19 increased the difficulty of managing HIV care, but existing comorbidities prevalent within the HIV community have meant high susceptibility to COVID-19 and adverse outcomes (3). PLWH have also been found to be at a potentially higher risk of SARS-CoV-2 infection, in part due to higher rates of substance use and homelessness within the population $(4,5)$.

Homelessness and congregate living among PLWH has been further exacerbated by employment and income loss due to residual economic effects of COVID-19 and, at times, has been precipitated by a COVID-19 infection (6). Income loss also contributed to increased food insecurity among PLWH, particularly among younger individuals; US studies showed around 40 percent of PLWH respondents reported food insecurity, with that rate increasing to 84 percent among people of color (7). Food insecurity is especially dangerous for PLWH because it has the potential to induce deleterious downstream effects within HIV management, including ART non-adherence and decreased clinic visits (7). In addition, both 
fear of and active COVID-19 coinfection were indicated to aggravate existing mental health struggles due to additional stress and isolation $(8,9)$.

By June $2020,13 \%$ of Americans reported that they had started using, or had increased substance use, in order to cope with stress and anxiety related to COVID-19 and many communities are seeing the overlapping effects of the COVID-19 crisis with the ongoing opioid crisis in the U.S. (10). Concurrently, social and environmental factors associated with drug use may increase the risk of COVID-19 infection, especially among individuals who experience homelessness, which is common among those with a substance use disorder (11). PWUD also face increased risk for adverse health outcomes overall, due to shortages and other barriers to obtaining medications, drugs, syringe exchange services, and overall health care. This is particularly worrisome due to the ongoing high risk of HIV among PWUD, as COVIDrelated disruptions in access to healthcare meant less access to HIV testing and less linkages to care for those who test positive for HIV.

HIV and AIDS service organizations around the nation were tasked with addressing this litany of social determinants heightened by COVID-19 with the additional service disruptions and limitations due to pandemic and associated public health protocols. However, prior experiences with the HIV epidemic were instrumental in responding and ensuring communities continue to access HIV prevention services (12). Numerous studies reported substantially reduced access and utilization of pre-exposure prophylaxis (PrEP), initial PrEP intake visits, and increases in refill lapses during the COVID-19 pandemic $(13,14)$. Many US cities also reported significant decreases in HIV testing rates - San Francisco, for example, reporting a 40 percent decrease citywide and a 90 percent decrease in community-based testing (13). PLWH also personally voiced concerns about limited on-site and at-home testing, and over a fifth of respondents to a global survey stated they lost access to their HIV provider, with the uninsured more likely to lose access (15). Moreover, the introduction of shelter-in-place policies necessitated the onset of virtual outpatient medical management, and although virtual attendance rates generally mirrored pre-pandemic in-person attendance rates, the transition to telehealth coincided with decreased viral suppression rates, especially among homeless PLWH $(16,17)$. A South Carolina study outlined services provided through telehealth which included client intake, non-medical case management, support groups, medication adherence assessments, and medication refills, among others. Barriers to telehealth adoption and implementation were present on both the provider and client ends. Low-resource organizations struggled to afford the technological infrastructure needed to establish efficiency and security. Clients reported a lack of smartphone access and digital literacy needed for video calls or app-based visits as well as some discomfort due to a lack of patient-provider intimacy (18).

In Indiana, over 11,500 individuals living with HIV - primarily white but disproportionately Black and Hispanic relative to the statewide population - were documented in 2018 at a rate of 206 cases per 100,000 people, approximately 55 percent of the national rate and in-line with the regional rate (19). Prior to COVID-19, of those in Indiana with known HIV status, 77 percent reported receiving medical care, and 62 percent were documented as virally suppressed (19). Twenty-three primary AIDS service organization 
offices, including satellite locations, around the state of Indiana provide PLWH with non-medical case management services.

Guided by the socioecological model (SEM) (20), this study examined Indiana-based AIDS services provider perceptions of how COVID-19 affected the overall health and access to care of their PLWH clients, and how the organizations prepared for, adapted, and responded to the needs of PLWH during the pandemic. Understanding these individual- and organizational-level challenges and responses can be instrumental to informing HIV service delivery innovations moving forward, as well as future pandemic response for vulnerable populations.

\section{Methods:}

Guided by the SEM, an initial interview guide was developed to understand multilevel challenges and responses to supporting PLWH during the COVID-19 pandemic, from the perspective of Indiana AIDS services organizations. The final interview guide included questions such as: "Under normal circumstances (pre-COVID), what specific services or resources does your organization provide for individuals with HIV?", "Did COVID change service provision in any way for your organization?", "In your view, how has the COVID-19 pandemic impacted your clients?", and "Did COVID-related policy changes affect your organization or operations?". The interview guide developed for this study is provided as Additional File 1.

To obtain the most comprehensive accounting of individual and organizational HIV-related activity during the COVID-19 pandemic, community-based organizations (CBOs) serving PLWH from around Indiana were recruited and interviewed. From September 2020 through November 2020, individuals were recruited via email using snowball sampling. Initial contact was made with a representative of an HIV-service organization who provided a comprehensive list of all HIV-service organizations and testing centers in the state. Progressively, as interviews were conducted, information regarding additional organizations was obtained from interviewees.

In total, 15 semi-structured interviews were conducted with 15 individuals from 10 different HIV/AIDS service organizations across Indiana at which point data saturation was reached. These organizations were well-dispersed geographically around the state and offered a diverse array of services including PrEP, non-medical case management, medical case management, HIV testing, STI testing, Hepatitis C testing, housing services, educational services, and mental health services - among others. The individuals interviewed held various roles within their respective organizations, including executive director, non-medical case manager, and testing coordinator.

Interviews of 30-60 minutes were performed virtually by a trained undergraduate male research assistant (JJM) with no current or previous associations with any of the interviewed individuals or organizations. The interviews were conducted via video calling software (Zoom), recorded, and transcribed using Otter.ai. The purpose of the study and the voluntary nature of their requested participation was explained to participants, they were given an opportunity to ask questions, and all participants provided verbal 
consent prior to commencing the interviews. All interview transcripts were reviewed and edited for accuracy. The transcripts were then thematically analyzed by two independent coders using a constant comparative method in NVivo, a qualitative coding software program. Guided by the SEM, themes were organized across individual-, interpersonal-, organizational-, community-, and public policy-levels. (Fig. 1). This study was exempt by Purdue University's Institutional Review Board (protocol IRB-2020-685).

\section{Results:}

\section{Individual-level Challenges experienced by PLWH:}

According to organizational staff, PLWH were generally under the impression that they had an increased mortality risk upon contracting COVID-19, stating "people living with HIV I think are especially aware of their compromised immune system. And so people are nervous to be out... I had one guy call and he said I'm scared to go out. I don't have gloves. I don't have a mask... I shouldn't even go get no gas because of the pumps and stuff." This - at times - voluntary lack of facetime with close acquaintances or even strangers due to known health risks was coupled with an additional lack of "intimacy and socialization" available at service organizations because regular inter-client fraternization was prohibited due to public health restrictions: "yes they got to see [service providers] but they never got to see their peers, like before when they were in the office they got to see each other, and that wasn't happening when they were home." Even virtual contact with service providers was limited due to geographic and technological limitations, "so I live in Brown County. We have great trees and lots of hills, also a good chunk of it is country. You just don't have internet, like not because you can't afford it, it's just not available to you... So we did run into that with some clients and so there were some home visits in terms of like, I'm just gonna run out and check on someone."

Both knowledge of their HIV status and forced closures fostered feelings of isolation among PLWH. Moreover, pre-existing mental health issues were often aggravated by the additional isolation, with a counselor noting that "they were just very anxious because a lot of them have anxiety already and they were just like what's going on?"Staff attributed to PLWH comments regarding a desire for in-person interaction, "I wish I could hug you... and we have to say I'm sorry we can't do that." At times, the inability to provide in-person services fostered resentment, "so it was really hard for that change I think when we had to put a sign on our door that said no public allowed. And our clients couldn't come in and we still have a client who like refuses to speak to us because he said that we've banned him from his home." In some instances, this lack of in-person contact precipitated a decrease in viral suppression. In general, "viral suppression across the state has definitely nosedived but that's for a couple reasons," one of which was PLWH getting their prescription refills but not any labs and thus not being officially documented as virally suppressed, but the other was because medication compliance decreased, "engagement and care really suffered...there are some of our clients that if they don't have somebody like filling their pill boxes and monitoring it and checking on it, they're just not gonna stay adherent to their medication." 
Providers also suggested that employment cuts during COVID-19 also heavily affected their client population because "most of our clients who are working work in the service industry... you know, there isn't work. And so, certainly at any point in time, losing your housing is not going to be good for your overall health outcomes."

While some organizations noted a decrease in engagement from existing clients stemming from new onset or exacerbated mental health issues or job loss, others found that pandemic-induced unemployment precipitated a return to care. Additional free-time allowed some individuals an opportunity to access services: "people were all off work. So they had time to take care of the medical stuff, you know. Sometimes when you're working, because you're going back and forth to work, you don't take care of your own personal stuff. So we had three people who enrolled in our program, because they were off of work and they had the time to do it."

\section{Organizational-level Challenges, and Responses Preparedness}

A general theme among interviewed HIV service organizations about addressing issues raised by the COVID-19 pandemic was utilizing ingrained disaster and epidemic response techniques learned from dealing with the HIV crisis in the past because "you think about back in the late 70s early 80s when AIDS hit, this country was woefully unprepared. That's why everybody ended up, a lot of people ended up decompensating physically and dying." Yet, explicit preparation plans for an airborne, respiratory-based pathogen were nonexistent, "it was pretty much doing everything on the fly. We have like a safety manual, but we didn't have anything about a pandemic in there. And so definitely on the fly," so organizations had to and did act swiftly to properly address urgent, upcoming needs for both their clients and the PLWH population as a whole.

One organization reported preparing extensively for the pandemic while it was in its infancy, "So we did an assessment. I want to say like the last week of February, first week of March, maybe, where our care coordinators contacted every client in every one of our programs to find out if they had what they needed to be able to shelter in place for 14 days. So that was a huge undertaking, and then we bought stuff." After the initial items and supplies had been purchased, they were compiled, organized, and distributed via no-contact "home visits." Moreover, because of longitudinal relationships and familiarity with existing clients, staff members were able to identify clients that were particularly at risk for prescription noncompliance, "we could identify like these are the people that I do a lot of medication management with. So we know if we're not doing that we know they're not taking them... whether we can document it or not, I know they're not taking them." Consequently, staff ensured these individuals were able to receive and adhere to taking their medications by having their medications shipped to the office and communicating to clients "alright your meds are here, I'm going to hand out the pillbox, they go back to their car, they fill the pillbox, they go in and hand it back, so you just, you know, you make it work." Multiple organizations also educated their clients on likely scenarios going forward, "we had been able to let most of our clients 
know like, this is what's happening with COVID and it is highly likely that Indiana will be on a stay at home order."

Additionally, because of the reciprocal nature of housing instability and infection, many organizations attempted to preemptively protect PLWH by assisting with their housing. For a period of time, preventing potential new instances of homelessness supplanted the shifting of existing clients around the housing case management network, with one organization stating "we did very little of our normal like more comprehensive housing case management. It was very much crisis response for that entire time period like doing the application getting the documentation. Getting bills paid was pretty much what they were doing." Much of this effort was made in an attempt to mitigate the effects of lifting finite eviction moratoria, working with clients during the moratoria to avoid the need for a large amount of urgent aid, "we went ahead and tried to help people along the way, because we knew the second that it was lifted, people were going to be facing eviction. So we tried to work with clients to prepare as if there wasn't a hold on evictions."

Although long-term or permanent supportive housing programs may not have been the focus at the time, service providers did offer housing assistance and solutions to the newly homeless as well, "we made sure to put them directly into some type of housing whether we put them in a hotel, or we found an apartment to put them in," although "there [was] a lack of housing, rental housing. And if you [could] find rental housing, it [cost] was extremely high."

\section{Outreach and Testing}

The COVID-19 pandemic severely affected the medium from which community-based organizations (CBO) interfaced with potential and existing clients. Many organizations stressed that they follow a harm reduction model and meet the client "where they're at, no judgement," indeed at times "meet[ing] the people directly on the street." Organizations emphasized that they prefer face-to-face meetings, especially with initial intakes to pacify the nerves of new clients, "I would like to think that this should be done in person at first, if at all possible... the person that's coming in as a consumer is meeting you. They're scared to death. They don't know what to expect. They need to know who you are."

Prior to COVID-19, organizations made significant efforts building rapport with the communities with which they engage in an effort to better attract and retain clients: "they trust us in a way that they won't trust other places... rapport is an important part of retention and maintenance." In the past, having this level of rapport enabled CBOs to engage potentially at-risk clients, stating "when we're out on our mobile unit for our syringe exchange, we'll go find somebody if we hadn't seen him in a while just to check on and make sure they're doing okay, why haven't we seen you."

With the onset of COVID-19 restrictions, however, new intakes and face-to-face interactions were severely limited, with providers reporting "we did not have new intakes for like a good month period...there was a solid several months there where people didn't do health care in person at all" and "there were things that we did do in person, but I could probably count them on one hand." 
Most organizations reported HIV testing significantly decreased during periods where in-person access to existing and potential clients was suspended or severely limited. Prior to COVID-19, HIV providers would typically test "out in the community" or "every three months we were testing certain people especially at our drug treatment facilities... or the jail" which comprised "a significant portion of our HIV testing right there."Testing at these external sites, however, was no longer possible with public health restrictions in place. Moreover, the space limitations of testing facilities - "physically our testing rooms were tiny" and the physical requirements of common testing modalities- "we were doing fingerpick pricks at the time so you had to be pretty close to people" - prevented adherence to safe public health practices.

Additionally, it was suggested that a decrease in HIV testing was also linked to COVID-induced changes in procedure. Once limited in-house testing resumed, one organization noted that their STD testing increased significantly from baseline while their HIV testing decreased significantly from baseline. It was hypothesized that these trends were observed because the STD testing underwent no location or procedural changes while location of HIV testing - previously out in the community - was forced to move in-house: "our STD testing has always been done in house, so everybody knew that if you wanted STD testing you had to come to us we weren't going to be in the community doing that...now for HIV they were not, they just knew that we were going to be in the community somewhere and if you found us you can get an HIV test. They were never trained to come to our office, or to sign up online like they were for STD."

To attempt to remedy the gap in testing due to social distancing, one service provider specified that they obtained more self-swab tests to limit client-provider contact, "people could swab themselves. So you could sit farther or they could do it themselves and then you just look at it together in 20 minutes." Another provider further obtained a customized physical barrier between the tester and client: "protection shields, so the client could stick because the test is doing a finger prick. So they could slide the hand through the shield. And so both people were protected." Other providers decided to eschew indoor testing altogether and maintained that outdoor testing would be most feasible and beneficial, "so we do testing in the park, instead of testing an office or education at sites so people can just show up at a park and get tested for two hours at a time." To gain access to hard-to-reach populations in jails or vulnerable populations in treatment centers during in-person restrictions, one organization arranged special accommodations with such places, setting up zoom calls to undergo virtual testing and education: "we'll be zooming and then they'll be referring people to us for testing, or we'll be dropping off test kits at the facilities, and we'll be zooming with them to do the testing after we do the education."

Although the pace of intakes initially slowed because of in-person outreach and testing restrictions, providers were eventually able to acquire the appropriate technology to perform virtual intakes and utilized basic phone calls and texting to obtain patient information: "intakes [were] mostly done over the phone... we just asked people hey you know if you want we could get some basic information from you right now... and they can text us pictures of those things, they can email it, they can drop it off the office, we can go pick it up, we can do, like, what I call, like a door dash."Because of the newfound importance of connection via the telephone - for both interactions with the service organization and outside entities 
in a now predominantly virtual world - some organizations provided clients with funds to pay their telephone bill: "that was their form of communication... So that was about 20 people we assisted who had lost their jobs to keep their cell phone on for a month, we thought it would just be a month. But it turned out, we had to do that a couple of times because people were not able to go back to work."

To assist both new and existing clients in accessing necessary case management services, many HIV service organizations provided select clients with tablets: "for those who don't have phones, or some people whose phones only work on Wi Fi, we're able to distribute [tablets]. So people can do telehealth appointments, mental health appointments, anything with our programming, they'll be able to do it from their tablet."

In regard to distributing goods to clients intermittently throughout the pandemic, organizations offered atwill pick up pursuant to social distancing guidelines, "so right now, anybody who needs the supplies that we offer we have to just have them come and stand outside our door and give it to them or we can drop them off like there's a table, and we just usually drop goods off there. And then, anybody can get it when they want." The distribution of supplies was not only as needed but proactive as well, placing provisions in highly trafficked areas, "we've also resorted to just setting up pockets of supplies inside gas stations, hotels, things where we know that people use intravenous drugs are. And our pamphlets we've put in local community centers so that they can just hand them out to patients that they know may need them."

\section{Public policy-level responses:}

Many organizations expressed the sentiment that, prior to the COVID-19 pandemic, their operations were forced to comply with unnecessary rules and restrictions that inhibited client interactions. Two particular policies were highlighted: the need to meet in person once every 90 days for a review, and the inability of organizations to use laptops for work-related purposes. Organizational staff found the quarterly in-person review to be a hindrance to both parties: "So, what, what's with all these different rules, you'd have to meet in person once every 90 days. What for? Whose needs does that serve? Not mine not theirs." Fortunately, this in-person requirement was suspended by the State of Indiana during the pandemic, and staff were able to sign on their client's behalf. HIV service organizations appreciated this change and its added convenience "if somebody doesn't want to come in and meet with or doesn't have the time but they can talk to us over the phone and give us all the information and then text me a picture of their ID... we can make things easier on people than we are." Moreover, proxy signings and virtual meetings not only increased convenience but also served to mitigate unnecessary disease propagation by resulting in " $a$ lot less actual contact with people."

In addition to the in-person review, the state-mandated restriction on laptop use hampered the ability of organizations to rapidly adjust to virtual work. Prior to the COVID-19 pandemic, Indiana was concerned about the security of laptops, "the State Department of Health had never let us even own laptops before this, they considered it a security risk and information risk like even in our office they made us get desktop computers which are insanely more expensive than laptops...somebody could get [a laptop] stolen." Although organizations were not able to obtain laptops prior to COVID, many used cell phones to 
communicate with clients easily and remotely, "we had work cell phones because we've gotten those a while back to be able to text with clients because we found a lot of clients preferred it. It's just the way the world is now. But none of us have a laptop." Finally, the State eased restrictions and allowed HIV service organizations to use laptops for work-related affairs, "and then all of a sudden everybody's rules are just gone. Yes, it's fine get laptops, work from home, set up remotely."

In terms of receiving financial support during the pandemic, organizations were able to receive a sufficient amount of funds able to be used for various client-facing initiatives: "We have been fortunate to receive many COVID housing awards. So we have the funds to be able to put people in housing... we did get relief money from the CARES Act for both HOPWA and Ryan White Part B, and we are putting that into our emergency financial assistance." Moreover, financial and material assistance did not just come from governmental aid but also the private sector as well, "I think the Health Foundation of greater Indianapolis...I think they're the ones who ended up paying for the laptops... The St. Joseph Community Health Foundation who funds I think general operating for us, they offered some up for like masks, sanitizers, cleaners, and things." Although the consensus seemed to be that an ample amount of funding was readily accessible for client-oriented programs, some organizations were concerned about the immediate and long-term availability of monies to sustain basic operating costs such as payroll and overhead. Operating funds were hypothesized to be reduced for two main reasons: a COVID-induced lack of in-person fundraising events and restrictions on the use-cases of existing funds: "I think the place we're gonna end up struggling is just general operating funds, because both of our big fundraisers for the year are having to be done virtually, so they're not canceled, but they're not going to be as productive as they typically are and that's the thing nobody ever wants to fund is operating you know they want to give you money for housing and you know bus passes and things but they don't want to pay for the person to hand them out to write the checks to process the paperwork." Going forward, organizations are appreciative of the immediate public and private sector responses but are concerned about their financial situation moving forward: "So, yeah, the floodgates at the beginning were nice but I worry about the long haul."

${ }^{1}$ The Housing Opportunities for Persons With AIDS (HOPWA) Program is a federally funded program that provides housing and other assistance for individuals diagnosed with HIV/AIDS that meet specific income requirements (21). The Ryan White HIVIAIDS Program is a program that provides grants various entities including local service organizations to fund HIV healthcare and various support services (22).

\section{Discussion:}

COVID-19 has deepened inequalities and amplified social and structural determinants of HIV transmission. Global studies have highlighted various ways in which the COVID pandemic has impacted HIV testing and access to services for key populations. Data from the HIV modelling consortium suggests there may be a substantial rise in HIV infections and mortality from 2020-2025 due to COVID-related care disruptions if no additional support is provided to health systems and health workers (23). This is compounded by poorer outcomes for both COVID and HIV for vulnerable populations such as minority 
ethnic, homeless, and PWUD populations, who will bear the brunt of weaker HIV services due to health disparities rooted in social determinants (24).

Despite the profound disruptions experienced by HIV programs, community-based HIV/AIDS service organizations responded quickly to the challenges posed by the COVID-19 pandemic and have adapted their service delivery practices to ensure that gains made in HIV prevention and management are not severely eroded. Studies have shown how community-based HIV programs made innovative service delivery adaptations to manage consequences of restrictions brought about by lock-downs including telehealth counseling, multi-month dispensing of ART, PrEP, needles and syringes and take home doses of opioid substitution therapy (25-28). COVID has also shifted provider and public perceptions on innovations like HIV self-testing and community-based care delivery that move HIV diagnosis and management away from overburdened healthcare and laboratory facilities, which could have important implications for HIV care continuity and improve service delivery for marginalized populations long after the pandemic (29).

This study examined the impacts of the COVID-19 pandemic on PLWH in Indiana and the experiences, challenges, and responses of HIV/AIDS service organizations. The socio-ecological model guided the analysis of multilevel challenges and responses to maintaining HIV care during the pandemic, from the perspective of service providers. The identified individual-level challenges faced by PLWH support existing literature on the intersections between HIV and COVID-19 (30-33). At the organizational level, Indiana HIV/AIDS service organizations reported numerous challenges and diverse responses to the COVID-19 crisis and impacts on their clients. While many HIV/AIDS service organizations had experience operating amid a viral epidemic, the transmissibility of COVID-19 limited any established disaster preparedness, presenting novel problems necessitating innovative solutions. As a result, HIV/AIDS service organizations utilized a motley of strategies to initiate and maintain care safely. HIV/AIDS service organizations elsewhere were also forced to suspend in-person HIV testing and various community outreach events $(25,26,33)$. Reponses elsewhere mirror those found in this study, including the prepacking and delivery of various supplies as well as offering telephonic and virtual appointments, with the efficacy of the latter interventions varying by site $(26,28,36)$. Moreover, other organizations made additional attempts to mitigate the spread of COVID-19 at existing testing sites, such as pre-screening for signs of infection via the telephone or suspending HIV testing requirements to obtain PrEP services (33). Overall, within Indiana and elsewhere, an initial suspension of in-person services was often supplemented with virtual equivalents, and - where appropriate - some in-person services such as testing were gradually reinstated pursuant to public health best practices at the time.

\section{Conclusions:}

The lessons provided by HIV/AIDS service organizations in Indiana are invaluable to informing HIV prevention and care continuity as well as future pandemic response for PLWH and at-risk populations. Furthermore, many ways in which they adapted their practices could improve service delivery for 
vulnerable, at-risk, and PLWH populations beyond the COVID-19 pandemic and provide a catalyst towards ending the AIDS epidemic.

\section{List Of Abbreviations:}

AIDS: Acquired immunodeficiency syndrome

COVID-19: Coronavirus Disease 2019

HIV: human immunodeficiency virus

PLWH: People living with HIV

PrEP: pre-exposure prophylaxis

PWUD: People who use drugs

SEM: socioecological model

\section{Declarations:}

Ethics approval and consent to participate: This study was reviewed and received an exemption determination by Purdue University's Institutional Review Board (protocol IRB-2020-685). Informed consent was obtained verbally by all participants prior to commencing research activities as approved by Purdue University's Institutional Review Board because the research involved no greater than minimal risk to participants and any disclosure of participant responses outside the research would not place subjects at risk.

Consent to publish: Not applicable

Availability of data and materials: The datasets used and analyzed during the current study are available from the corresponding author on reasonable request.

Competing Interests: Jacqueline Linnes is a co-founder and part owner of two diagnostics companies, OmniVis Inc. and EverTrue LLC, which both develop point-of-care diagnostic platforms for HIV detection and monitoring, and is a co-inventor on patents applicable to HIV detection and monitoring.

Funding: This work was supported by the Purdue University Institute of Inflammation, Immunology and Infectious Disease and College of Health and Human Sciences, and National Institutes of Health grants R33Al140474, R61Al140474, and DP2DA051910 (principal investigator: Linnes).

Authors' contributions: JJM contributed to study design and led the data collection, analysis, and writing of the manuscript. JCL secured funding and contributed to writing of the manuscript. NMR secured 
funding, conceived of and designed the study, and contributed to writing of the manuscript. All authors read and approved the final manuscript.

Acknowledgements: The authors are extremely appreciative to all participating HIV/AIDS Service Organizations around the state of Indiana and their staff who graciously donated their time and expertise, thus making this contribution possible.

\section{References:}

1. Basic Statistics | HIV Basics | HIV/AIDS | CDC [Internet]. 2021 [cited 2021 Apr 22]. Available from: https://www.cdc.gov/hiv/basics/statistics.html

2. UNAIDS Joint United Nations Programme on HIV/AIDS. Miles to go-closing gaps, breaking barriers, righting injustices [Internet]. 2018 [cited 2021 Sep 15]. Available from:

https://www.unaids.org/en/resources/documents/2018/global-aids-update

3. Ambrosioni J, Blanco JL, Reyes-Urueña JM, Davies M-A, Sued O, Marcos MA, et al. Overview of SARSCoV-2 infection in adults living with HIV. The Lancet HIV. 2021 May;8(5):e294-305.

4. Parashar S, Collins AB, Montaner JSG, Hogg RS, Milloy M-J. REDUCING RATES OF PREVENTABLE HIV/AIDS-ASSOCIATED MORTALITY AMONG PEOPLE LIVING WITH HIV WHO INJECT DRUGS. Curr Opin HIV AIDS. 2016 Sep;11(5):507-13.

5. Walters S. COVID-19 and People Who Use Drugs - A Commentary. Health Behav Policy Rev. 2020 Oct;7(5):489-97.

6. Riley ED, Hickey MD, Imbert E, Clemenzi-Allen AA, Gandhi M. COVID-19 and HIV spotlight the U.S. imperative for permanent affordable housing. Clin Infect Dis. 2020 Sep 5;

7. Winwood JJ, Fitzgerald L, Gardiner B, Hannan K, Howard C, Mutch A. Exploring the Social Impacts of the COVID-19 Pandemic on People Living with HIV (PLHIV): A Scoping Review. AIDS Behav. 2021 May 21;1-16.

8. Waterfield KC, Shah GH, Etheredge GD, Ikhile O. Consequences of COVID-19 crisis for persons with HIV: the impact of social determinants of health. BMC Public Health. 2021 Feb 5;21(1):299.

9. Benzano D, Ornell F, Schuch JB, Pechansky F, Sordi AO, von Diemen L, et al. Clinical vulnerability for severity and mortality by COVID-19 among users of alcohol and other substances. Psychiatry Res. 2021 Mar 31;300:113915.

10. Czeisler MÉ. Mental Health, Substance Use, and Suicidal Ideation During the COVID-19 Pandemic United States, June 24-30, 2020. MMWR Morb Mortal Wkly Rep [Internet]. 2020 [cited 2021 Sep 15];69. Available from: https://www.cdc.gov/mmwr/volumes/69/wr/mm6932a1.htm

11. Volkow ND. Collision of the COVID-19 and Addiction Epidemics. Ann Intern Med. 2020 Apr 2;M201212.

12. Valdiserri RO, Holtgrave DR. Responding to Pandemics: What We've Learned from HIV/AIDS. AIDS Behav. 2020 Jul 1;24(7):1980-2. 
13. Brown LB, Spinelli MA, Gandhi M. The interplay between HIV and COVID-19: summary of the data and responses to date. Current Opinion in HIV and AIDS. 2021 Jan;16(1):63-73.

14. Rogers BG, Tao J, Maynard M, Chu C, Silva E, Toma E, et al. Characterizing the Impact of COVID-19 on Pre-Exposure Prophylaxis (PrEP) Care. AIDS Behav. 2021 Jun 10;1-4.

15. Santos G-M, Ackerman B, Rao A, Wallach S, Ayala G, Lamontage E, et al. Economic, Mental Health, HIV Prevention and HIV Treatment Impacts of COVID-19 and the COVID-19 Response on a Global Sample of Cisgender Gay Men and Other Men Who Have Sex with Men. AIDS Behav. 2020 Jul 11;111.

16. Brody JK, Rajabiun S, Strupp Allen HJ, Baggett T. Enhanced Telehealth Case Management Plus Emergency Financial Assistance for Homeless-Experienced People Living With HIV During the COVID19 Pandemic. Am J Public Health. 2021 Mar 18;111(5):835-8.

17. Spinelli MA, Hickey MD, Glidden DV, Nguyen JQ, Oskarsson JJ, Havlir D, et al. Viral suppression rates in a safety-net HIV clinic in San Francisco destabilized during COVID-19. AIDS. 2020 Dec $1 ; 34(15): 2328-31$.

18. Yelverton V, Qiao S, Weissman S, Olatosi B, Li X. Telehealth for HIV Care Services in South Carolina: Utilization, Barriers, and Promotion Strategies During the COVID-19 Pandemic. AIDS Behav. 2021 Jun 25;1-13.

19. Indiana [Internet]. AIDSVu. [cited 2021 Apr 22]. Available from: https://aidsvu.org/local-data/unitedstates/midwest/indiana/

20. McLeroy KR, Bibeau D, Steckler A, Glanz K. An ecological perspective on health promotion programs. Health Educ Q. 1988;15(4):351-77.

21. Housing Opportunities for Persons With AIDS (HOPWA) [Internet]. Benefits.gov. [cited 2021 Sep 15]. Available from: https://www.benefits.gov/benefit/5888

22. About the Ryan White HIV/AIDS Program [Internet]. HIV/AIDS Bureau. 2016 [cited 2021 Sep 15]. Available from: https://hab.hrsa.gov/about-ryan-white-hivaids-program/about-ryan-white-hivaidsprogram

23. Jewell BL, Mudimu E, Stover J, Brink D ten, Phillips AN, Smith JA, et al. Potential effects of disruption to HIV programmes in sub-Saharan Africa caused by COVID-19: results from multiple mathematical models. The Lancet HIV. 2020 Sep 1;7(9):e629-40.

24. Solomon D, Tariq S, Alldis J, Burns F, Gilson R, Sabin C, et al. Ethnic inequalities in mental health and socioeconomic status among older women living with HIV: results from the PRIME Study. Sexually Transmitted Infections [Internet]. 2021 Mar 29 [cited 2021 Aug 30]; Available from: https://doi.org/10.1136/sextrans-2020-054788

25. Kay ES, Musgrove K. From HIV to Coronavirus: AIDS Service Organizations Adaptative Responses to COVID-19, Birmingham, Alabama. AIDS Behav. 2020 Sep 1;24(9):2461-2.

26. Glick SN, Prohaska SM, LaKosky PA, Juarez AM, Corcorran MA, Des Jarlais DC. The Impact of COVID-19 on Syringe Services Programs in the United States. AIDS Behav. 2020 Sep 1;24(9):2466-8. 
27. Peavy KM, Darnton J, Grekin P, Russo M, Green CJB, Merrill JO, et al. Rapid Implementation of Service Delivery Changes to Mitigate COVID-19 and Maintain Access to Methadone Among Persons with and at High-Risk for HIV in an Opioid Treatment Program. AIDS Behav. 2020 Sep 1;24(9):2469-72.

28. Rogers BG, Arnold T, Schierberl Scherr A, Strong SH, Holcomb R, Daley Ndoye C, et al. Adapting Substance Use Treatment for HIV Affected Communities During COVID-19: Comparisons Between a Sexually Transmitted Infections (STI) Clinic and a Local Community Based Organization. AIDS Behav. 2020 Nov 1;24(11):2999-3002.

29. Gupta-Wright A, Barnabas RV, Ingold H, Duneton P, Abubakar I. HIV self-testing: lessons learnt and priorities for adaptation in a shifting landscape. BMJ Glob Health. 2021 Jul 18;6(Suppl 4):e004418.

30. Harkness A, Behar-Zusman V, Safren SA. Understanding the Impact of COVID-19 on Latino Sexual Minority Men in a US HIV Hot Spot. AIDS Behav. 2020 Jul 1;24(7):2017-23.

31. Algarin AB, Varas-Rodríguez E, Valdivia C, Fennie KP, Larkey L, Hu N, et al. Symptoms, Stress, and HIV-Related Care Among Older People Living with HIV During the COVID-19 Pandemic, Miami, Florida. AIDS Behav. 2020 Aug 1;24(8):2236-8.

32. Shiau S, Krause KD, Valera P, Swaminathan S, Halkitis PN. The Burden of COVID-19 in People Living with HIV: A Syndemic Perspective. AIDS Behav. 2020 Aug 1;24(8):2244-9.

33. Beima-Sofie K, Ortblad KF, Swanson F, Graham SM, Stekler JD, Simoni JM. "Keep It Going if You Can": HIV Service Provision for Priority Populations During the COVID-19 Pandemic in Seattle, WA. AIDS Behav. 2020 Oct 1;24(10):2760-3.

34. Andrew Perrin. Mobile Technology and Home Broadband 2021 [Internet]. Pew Research Center: Internet, Science \& Tech. 2021 [cited 2021 Sep 15]. Available from: https://www.pewresearch.org/internet/2021/06/03/mobile-technology-and-home-broadband-2021/

35. Hightow-Weidman L, Muessig K, Claude K, Roberts J, Zlotorzynska M, Sanchez T. Maximizing Digital Interventions for Youth in the Midst of Covid-19: Lessons from the Adolescent Trials Network for HIV Interventions. AIDS Behav. 2020 Aug 1;24(8):2239-43.

36. Ridgway JP, Schmitt J, Friedman E, Taylor M, Devlin S, McNulty M, et al. HIV Care Continuum and COVID-19 Outcomes Among People Living with HIV During the COVID-19 Pandemic, Chicago, IL. AIDS Behav. 2020 Oct 1;24(10):2770-2.

\section{Figures}




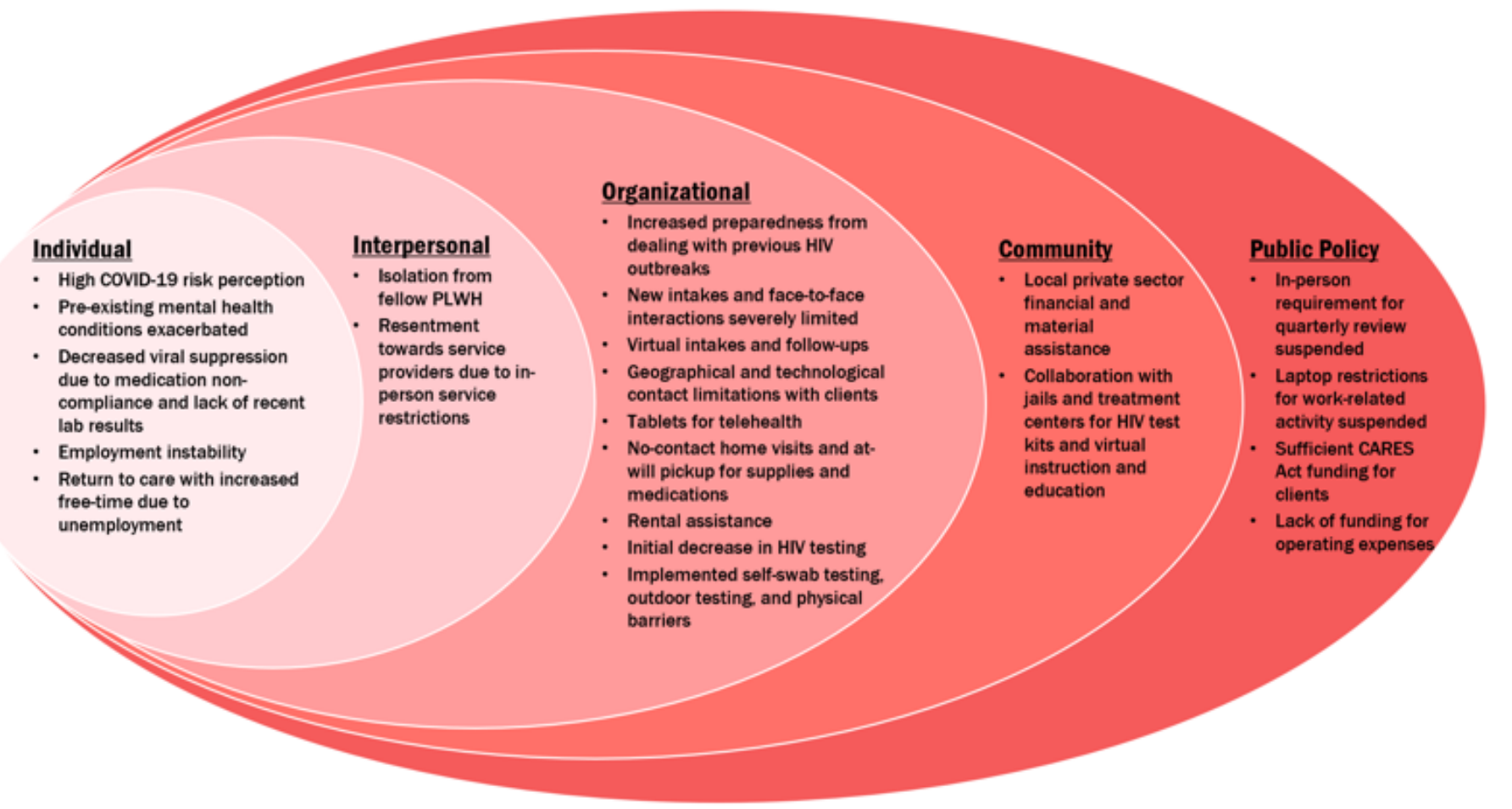

Figure 1

Socio-ecological model framework for multilevel challenges and responses to supporting PLWH during the COVID-19 pandemic.

\section{Supplementary Files}

This is a list of supplementary files associated with this preprint. Click to download.

- HIVOrgsCOVIDQuestionnaire.pdf

- ISSMCOREQChecklist.pdf 